to be taken. ..." Regulation 12 requires employers to provide information, instruction, and training to employees so that they understand the risks to health posed by these substances and the correct precautions needed. Other sections require keeping records of environmental monitoring and health surveillance and the examination and testing of respiratory protective equipment and local exhaust ventilation at specified intervals.

The responsibility for ensuring compliance with the regulations lies primarily with the employer, who may delegate all or part to one or more competent persons. In the health service this might be a departmental supervisor or manager, the head of a laboratory or clinical department or ward, a safety officer, or occupational health staff. The Health and Safety Executive has produced several approved codes of practice and supporting documents to help such staff understand and comply with the regulations. The suggested strategy for health authorities starts with appointing a coordinator and setting up a "control of hazardous substances team." Authority has to be delegated to competent people and resource implications have to be considered and provisions made for adequate equipment, authority, and support. An early essential step will be preparing an inventory of substances used in each department, with information on how much is used, how often, by how many people, and for which procedures. One benefit of this exercise is that it may identify obsolete substances, which can be discarded.

Priority must be given to protection against health hazards to health care staff that have already been documented. Examples are exposure to glutaraldehyde in endoscopy units, ${ }^{3}$ mercury in the repair of sphygmomanometers, ${ }^{+}$anaesthetic agents, ${ }^{5}$ and cytotoxic drugs. ${ }^{6}$ Procedures for protection against tuberculosis, hepatitis $\mathrm{B}$, and other infections need to be reviewed. Provision may need to be made for measurement of exposure. Two Scottish health boards already have industrial hygienists as members of their occupationar health departments, but we have yet to see the first industrial hygienist employed by the NHS in England and Wales.

The Department of Health has commissioned the University of Birmingham's Institute of Occupational Health to produce a form to be used in the initial assessment of health service premises under the Control of Substances Hazardous to Health regulations. The institute has asked doctors in the Association of NHS Occupational Physicians (ANHOPS) and occupational health nurses to help in this task; it plans a standardised approach to assessment to ensure uniformity and help in any later evaluations and comparisons. Once completed and documented, each assessment should need no further work unless there is a change in procedures or in exposure-or some new knowledge calls for changes.

If all this seems to be rather rushed, there are several justifications for urgency within the NHS. These include the removal of crown immunity for the health service, the increasing interest and familiarity of health and safety inspectors with health service premises, and adverse publicity about poor hygiene and safety in the NHS with closure of some hospital kitchens and outbreaks of legionnaires' disease. Health service administrators, managers, and heads of departments will need to make an early start in understanding and implementing the Control of Substances Hazardous to Health regulations. The prime purpose of the regulations, after all, is the protection of their staff and themselves against chemical and microbiological hazards in their workplace.

TAR-CHING AW

Senior Lecturer in Occupational Medicine,

Institute of Occupational Health,

University of Birmingham,

Birmingham B15 2TT
1 Control of Substances Hazardous to Health Regulations 1988. London: HMSO, 1988. (Statutors Instruments 1988 No 1657

Health and Safety at Work det 1974 London: HMSO, 1975

Burge PS. Occupational risks of glutaraldehyde. Br Med 7 1989;299:3+2.

Ide CW. Mercury hazards arising from the repair of sphygmomanometers. Br.Med 7 1986;293:1409. Harrington JM. The health of anaesthetists. Anaesthesia 1987;42:131-2.

6 Vainio $H$. Inhalation anesthesia, anticancer drugs and sterilants as chemical hazards in hospitals Siand J W'ork Enirom Health 1982:8:94-107.

\section{The NHS boot}

\section{Computers could transform provision}

Of all the appliances and devices available through the NHS, surgical footwear is the greatest cause of dissatisfaction among patients and prescribers. The Department of Health and Social Security published an extensive study of patient satisfaction with NHS footwear in 1979 based on 1500 patients. ${ }^{1}$ The minister at the time was happy to report that the study showed that there was a "high level of satisfaction" $-82 \%$ of patients said that they were satisfied with their footwear. Closer examination of the results showed that the $82 \%$ was derived from the numbers who did not complain. In fact a further $9 \%$ were stated as having felt like complaining, but they had not done so. Put another way, more than one in four patients had a complaint. More recent studies have drawn attention to widespread deficiencies, ${ }^{23}$ and the most recent Department of Health study clearly singled out "footwear" as the most troublesome product."

Patients often find their boots and shoes ugly and uncomfortable and that they do not last long enough. Clearly there is substantial wastage due to little or no use of shoes supplied. A study from Nottingham discloses that almost a fifth of shoes were abandoned after three years ( $p$ 950). In many cases the reason was difficulty in using them. The authors recommend more extensive use of "modular" deep shoes, which are better looking, cost much less, and may have easier fastenings. Wider use of this form of footwear was advocated by Klenerman and Hughes.+ They are not, however, the answer to all footwear problems: the "surgical" shoe made to measure still has a place for patients with more severely disordered feet.

Doctors prescribing modular shoes have to be very sure of their ground. They should be able to turn to the orthotist to obtain a dispassionate view of what is best. Unfortunately, with the current contract most orthotists are employed by the companies who supply the orthoses, and they must have some degree of interest in company turnover. They would be free of these pressures if the contract separated the goods from the fitter, as is the case in the few hospitals that employ their own orthotists.

The earlier studies of consumers' views found that delays in delivery of footwear were a major source of dissatisfaction. ${ }^{12}$ New data from 821 prescribers of footwear obtained by Lord and Foulston showed that the single most apparent need was for improved speed of delivery. ${ }^{5}$ This research was part of a larger feasibility study for the design and production of bespoke footwear using computers. These techniques (already begun in the prosthetics industry) provide an opportunity to hoist surgical shoe making out of the last century into the front line of modern technology. With these techniques also comes an opportunity for centralised manufacture - with associated benefits to the cost and speed of production. The study was funded by the Department of Health and has shown the techniques to be feasible, but the dovartment has recently announced that funding for this 
work is to cease. With the cost of surgical footwear at more than $£ 15 \mathrm{~m}$ a year, the difficulties in recruitment of skilled shoemakers, and the delays that cause such dissatisfaction, this policy can only be described as staggeringly shortsighted. Any bioengineering development of this sort is expensive, but it is also vital if Britain is to maintain any kind of position in this specialty. The proposed devolvement of responsibility to regional health authorities makes the future look even bleaker.

R G S PLATTS

Consultant in Orthotics and Rehabilitation Engineering,

Royal National Orthopaedic Hospital,

Stanmore,

Middlesex HA7 4LP

1 Bainbridge S. National Healih Service footwear. London: HMSO, 1979.

2 Royal Association for Disability and Rehabilitation. A future for the orthotic service. The report of working party on the availability and supply of orthotic appliances. London: Royal Association for Disability and Rehabilitation, 1983.

3 NHS Management Consultancy Services. Study of the orthotic service. London: HMSO, 1988.

4 Klenerman $L$, Hughes J. Surgical footwear. An assessment of the place of ready made extra depth shoes. Current Health Trends 1986;18:45-6.

5 Lord M, Foulston J. Surgical footwear: a surrvey of prescribing consultants. Br Med f 1989;299:657.

\section{Cardiotocographs at a distance}

\section{No convincing evidence of their value}

Recently techniques for recording the fetal heart rate at a distance have been winning prizes in competitions such as the British Technology Group's third Academic Enterprise Competition, have been displayed at the Design Centre, and have been commended as "commercially successful" in the $B M F .{ }^{2}$ Is this enthusiasm justified?

Continuous electronic monitoring of the fetal heart rate in labour has been widely used for 20 years, but its clinical value remains controversial. ${ }^{3+}$ The use of the technique for antenatal surveillance is even less well substantiated. Abnormal patterns of the antenatal fetal heart rate have been shown to correlate with a poor neonatal outcome, ${ }^{56}$ but no fewer than four randomised clinical trials have failed to show that this knowledge can be used to improve clinical outcome. ${ }^{7-10}$ Antenatal monitoring of the fetal heart rate is commonly requested after reports by the mother of reduced fetal movements and in women with hypertension or uncomplicated postmaturity. "112 This pattern of "indications" has evolved despite the facts that a recent multicentre trial of counts of fetal movement in 68000 women failed to show that liberal use of cardiotocography in women with low counts reduced the stillbirth rate $^{13}$; that in most women with hypertension there is no additional risk to the fetus ${ }^{1+16}$; and that unexpected intrauterine death in uncomplicated postmaturity is best avoided by exclusion of occult intrauterine growth retardation. ${ }^{17}$

Yet with all this negative evidence antenatal cardiotocographic monitoring remains very popular, probably because a normal cardiotocogram is reassuring to both the pregnant woman and the clinician. ${ }^{12}$ In many areas $10-15 \%$ of all women have at least one antenatal cardiotocogram recorded-about 80000 women a year in Britain. ${ }^{12}$ Many have multiple recordings - a normal cardiotocogram indicates satisfactory fetal cardiovascular function at the time of monitoring but its predictive value for future performance is probably limited to 48 hours and possibly less. ${ }^{18} 19$

Most cardiotocography is carried out in hospital clinics or wards, simply because this is where the instruments are sited. Repeated visits to the hospital are, however, expensive and time consuming and are surely inappropriate if the mother has been advised to rest and avoid stress. Techniques have been developed, therefore, to allow the cardiotocogram to be recorded in hospital while the mother remains at home. The simplest technique, developed by Dalton et al initially in Cardiff and then in Cambridge, is based on detecting the activity of the fetal heart with a cheap portable Doppler ultrasound system and transmitting it in real time through a standard telephone to a central cardiotocograph. ${ }^{2021}$ It has the advantage that the detector is cheap (about £250), but the woman must have a telephone at home, and the telephone bills may be expensive as most recordings take about half an hour. Gough et al have developed an alternative technique which processes the fetal heart signals in a portable unit and sends the computed fetal heart rate from a half hour recording in compressed form (40 seconds long) by telephone at any suitable later time. ${ }^{22}$ This is the system that is currently commercially available and that has been most widely reported, "112324 though other manufacturers have recently entered the fray. The cost of setting up a central station with five remote fetal heart rate detectors is about $£ 14000$. How well does the system work?

Overall signal loss in the system averages a third." This compares with a signal loss of only $2 \%$ with a modern cardiotocograph with pulsed Doppler and autocorrelation. ${ }^{25}$ Most normal traces are said to be clinically interpretable, but the value of traces thought to be abnormal remains suspect. ${ }^{.1}$ In one series 10 of the 368 women had fetuses with abnormal cardiotocograms. Eight delivered healthy infants, one infant died of severe prematurity after caesarean section at 27 weeks, and one died in utero three weeks later without any further cardiotocograms having been taken." In another series 134 women were selected for domiciliary fetal monitoring because of clinical risk factors. ${ }^{12}$ An average of 6.4 transmissions per patient were made, and 45 cardiotocograms were interpreted as being abnormal, but these contributed to a decision to deliver in only seven cases, and only two infants showed evidence of dysfunction at delivery.

In our view the widespread use of domiciliary fetal monitoring is inappropriate until the value (or otherwise) of antenatal cardiotocography is clarified. We hope that obstetricians will resist commercial pressure to purchase systems and instead insist that biomedical technology is assessed in the same way as new drugs and shown to have an acceptable benefit-risk ratio before it is introduced.

PHILIP J STEER

Professor of Obstetrics and Gynaecology,

Charing Cross and Westminster Medical School,

West London Hospital,

London W6 7DQ

Group Manager,

Biomedical Technology Group

(Fetal Monitor Evaluation Centre),

Department of Obstetrics and Gynaecology,

St Mary's Hospital Medical School,

London W2 1 PG

1 Hibberd B, Dawson A, Gough N. Domiciliary fetal heart rate recording. Prospect: British Technologv (iroup 1989;4:21.

Groves T. Short sighted equipment industry? Br. Med f 1989;299:221

3 MacDonald D, Grant A, Sheridan-Pereira M, Borlan P, Chalmers I. The Dublin randomized controlled trial of intrapartum fetal heart rate monitoring. Am 7 Obstet (jynecol 1985; 152:52t-39.

+ Steer PJ, Eighe F, Lissauer TJ, Beard RW. Interrelationships among abnormal cardiotecograms in labor, meconium staining of the amniotic fluid, arterial cord blood $\mathrm{pH}$, and Apgar scores. Obstet Gynecol 1989. (In press.)

Kidd LC, Patel NB, Smith R. Non-stress cardiotocography-a prospective blind study. Br.f ( )hstet Gynaecol 1985;92:1152-5

6 Brioschi PA, Extermann P, Terracina D, Weil C, Mao WT, Beguin F. Antepartum nonstress fetal heart rate monitoring: systematic analysis of baseline patterns and decelerations as an adjunct to reactivity in the presence of fetal risks. A $m$ f Obstet (ivnecol 1985;153:633-7.

Flynn AM, Kelly J, Mansfield H, Needham P, O'Connor M, Viegas $\mathrm{O}$. A randomised controlled trial of non-stress antepartum cardiotocography. Br $\mathcal{F}$ Obstet Gynuecol 1982;89:427-33.

8 Brown VA, Sawers RS, Parsons RJ, Duncan SLB, Cooke ID. The value of antenatal cardietecography in the management of high risk pregnancy: a randomised controlled trial. $\mathrm{Br} F($ ) bstet Graphy in the managemer 1982;89:716-22. 